\title{
A new AR therapy (MP29-02*): all of ARIA in one puff
}

\author{
Ralph Mösges ${ }^{1 *}$, Ludger Klimek², Carlos Baena-Cagnani ${ }^{3}, \mathrm{G}$ Walter Canonica ${ }^{4}$ \\ From The 10th Symposium of Experimental Rhinology and Immunology of the Nose (SERIN 2015) \\ Stockholm, Sweden. 19-21 February 2015
}

Allergic rhinitis (AR) is increasing in prevalence and becoming more difficult to treat. There is a subset of patients who are refractory to ARIA-defined rhinitis management approaches [1]. Even though new treatments have been made available for symptomatic relief, no new class of medication was forthcoming, until recently. The situation has now changed. MP29-02* is a novel intranasal formulation of azelastine hydrochloride (AZE) and fluticasone propionate (FP) in an advanced delivery system. It benefits from antihistamine, mast-cell stabilizing, anti-leukotriene and anti-inflammatory properties, made up in a unique formulation and delivered using an improved device (vs marketed intranasal steroid sprays (INS)). MP29-02"'s novel formulation and spray characteristics (e.g. finer droplet size, consistent spray release, wider spray angle) were developed to improve drug deposition on the nasal mucosa and ensure optimal retention. The impact has been observed both pharmacokinetically, [2] and clinically [3,4]. MP29$02^{*}$ was created to be more effective than any existing symptomatic treatment for AR, have a rapid onset of action and a sustained effect. Delivered as a single spray from one device, the aim was to improve compliance, maximize convenience for patients and simplify dosing. This product provides more effective relief than currently considered gold standard treatment, INS. A recent publication by Meltzer et al, 4 re-assessed the efficacy of MP29-02* versus AZE and FP in an innovative and clinically relevant way by responder analyses. The authors determined different response cut-offs from 30 to $90 \%$ reflective total nasal symptom score (rTNSS) reduction from baseline. More MP29-02* patients achieved each response (vs FP or AZE), and days earlier. A response ceiling of $\geq 60 \%$ was identified above which INS failed to differentiate from placebo. This may explain why moderate/severe AR patients still complain of bothersome symptoms despite ARIA-guided treatment. Patients who remain symptomatic on monotherapy should experience a significant reduction in their symptoms with MP29-02*, exceeding that which they have experienced in the past, and many days faster than an INS. MP29-02* comprises all the pharmacological principles foreseen in the ARIA treatment algorithm.

"Dymista

\section{Authors' details}

${ }^{1}$ University of Cologne, IMSIE, Cologne, Germany. ${ }^{2}$ Centre for Rhinology and Allergology, Allergy, Wiesbaden, Germany. ${ }^{3}$ Catholic University of Cordoba, Respiratory Division, Cordoba, Argentina. ${ }^{4}$ University of Genoa, IRCCS AOU, Genoa, Italy.

\section{Published: 26 June 2015}

\section{References}

1. Bousquet PJ, Bachert C, Canonica GW, Casale TB, Mullol J, Klossek JM, et al: Uncontrolled allergic rhinitis during treatment and its impact on quality of life: a cluster randomized trial.. JACl 2010, 126(3):666-668.

2. Derendorf H, Munzel U, Petzold U, Maus J, Mascher $H$, Hermann R, et al: . BJCP 2012, 74(1):125-133.

3. Carr W, Bernstein P, Lieberman, Meltzer E, Bachert C, Price D, et al: A novel intranasal therapy of azelastine with fluticasone for the treatment of allergic rhinitis.. JACl 2012, 129(5):1282-1289.

4. Meltzer E, Ratner P, Bachert C, Carr W, Berger W, Canonica GW, et al: Clinically relevant effect of a new intranasal therapy (MP29-02) in allergic rhinitis assessed by responder analysis.. Int Arch Allergy Immunol 2013, 161(4):369-377.

doi:10.1186/2045-7022-5-S4-P42

Cite this article as: Mösges et al:: A new AR therapy (MP29-02*): all of ARIA in one puff. Clinical and Translational Allergy 2015 5(Suppl 4):P42.

${ }^{1}$ University of Cologne, IMSIE, Cologne, Germany

Full list of author information is available at the end of the article 